\title{
INMIGRACIÓN Y SALUD: NECESIDADES Y UTILIZACIÓN DE LOS SERVICIOS DE ATENCIÓN PRIMARIA POR PARTE DE LA POBLACIÓN INMIGRANTE EN LA REGIÓN SANITARIA GIRONA (*)
}

\author{
Laura Vall-llosera Casanovas $(1,2)$, Carme Saurina Canals $(2,1)$ y Marc Saez Zafra $(2,1)$ \\ (1) CIBER de Epidemiología y Salud Pública (CIBERESP). \\ (2) Grup de Recerca en Estadística, Economia Aplicada i Salut, GRECS, Universitat de Girona, España.
}

\section{RESUMEN}

Fundamentos: A finales del año 1998 el volumen de población extranjera en España suponía un 1,60\% de la población total. En la actualidad este porcentaje asciende al 13,01\%. Este cambio en la estructura demográfica poblacional supone una alteración del uso de los servicios públicos en nuestro país. El presente trabajo tiene por objetivo analizar la morbilidad atendida, las necesidades y la utilización de los servicios sanitarios de atención primaria por parte de la población inmigrante, comparándolo con los usuarios autóctonos teniendo en cuenta el sexo, la edad, el origen geográfico y los condicionantes sociodemográficos.

Métodos: Los datos referentes a la morbilidad y utilización de los servicios sanitarios provienen de los registros médicos del Institut Català de la Salut (ICS). La información socioeconómica procede de un cuestionario administrado a una muestra de 645 usuarios de los servicios sanitarios de atención primaria, seleccionados mediante un muestreo estratificado no proporcional a partir de un proceso de identificación poblacional previo. Los datos obtenidos se analizaron con el módulo de muestras complejas de SPSSv15, a través de contrastes paramétricos y no paramétricos.

Resultados: Los resultados fueron: $50,1 \%$ de visitas en población inmigrante frente a un $61,2 \%, 50 \%$ de consumo de fármacos en población inmigrante versus $66,7 \%$ y $29,6 \%$ de trastornos crónicos en población inmigrante frente a un $51,4 \%$. Los resultados socioeconómicos muestran $9,4 \%$ de parados en población inmigrante frente a un $5,6 \%, 38 \%$ de analfabetos en población inmigrante frente a un 17,4\%, o un $53,5 \%$ en viviendas de alquiler en población inmigrante frente a un $15 \%$. Cuando se ajustan estas variables, las tasas de frecuentación no muestran divergencias en función del origen del paciente.

Conclusiones: Los contrastes realizados permiten afirmar que son, principalmente, estos condicionantes sociodemográficos, y no únicamente el origen del paciente, los que determinan las necesidades y utilización de los servicios sanitarios de la población.

Palabras clave: Migración Internacional. Estadística \& datos numéricos. Clasificación. Pacientes Ambulatorios. Condiciones sociales. Sistemas de identificación de pacientes. Economía médica.

\section{Correspondencia:}

Laura Vall-1losera Casanovas

CIBER de Epidemiología y Salud Pública (CIBERESP)

y Grup de Recerca en Estadística, Economia Aplicada i

Salut (GRECS) y Universitat de Girona

Campus de Montilivi, 17071 Girona

Correo electrónico: laura.vall_llosera@udg.es

\section{ABSTRACT \\ Immigration and health: needs and primary health care use by immigrant population in the Girona Health Region.}

Background: At the end of 1998, foreign population in Spain supposed a $1.60 \%$ of the total population. Nowadays, this percentage rises at $13.01 \%$. This change in the population socio-demographic structure means an alteration of the use of public services in our country. For this reason, this paper aims to analyze, for the Health Region Girona (RSG), the attended morbidity, the needs and the uses of primary health care services by immigrant population, compared with native users considering sex, age, ethnicity and sociodemographic conditions.

Methods: The data on morbidity and on health care services utilization comes from medical records of the Catalan Health Institute (ICS); socio-economic information comes from a questionnaire administered to a sample of 645 users of primary health care services selected, using a non proportional stratified sampling method, from a previous population identification process. Data was analyzed with complex samples module of SPSSv15, through non-parametric and parametric contrasts.

Results: The results show an immigrant population healthier than the native $(50.1 \%$ of visits compared to $61.2 \%, 50 \%$ of drug consumption versus $66.7 \%$ and $29.6 \%$ of chronic disorders versus $51.4 \%$ ) although they persist in worst socio-economic conditions (9.4\% unemployed compared to $5.6 \%, 38 \%$ are illiterate compared to $17.4 \%$, or $53.5 \%$ of homes in rent versus $15 \%$ ). Adjusting by these variables, frequentation rates do not differ by patient's origin.

Conclusions: Realized contrasts allow affirming that are, mainly, these socio-demographic conditions, and not uniquely the origin of the patient, those that determine the population needs and the population uses of health care services.

Keywords: Emigration and Immigration. Statistics \& numerical data. Classification. Outpatients; Social conditions. Patient identification systems. Economics, Medical.

(*) Trabajo financiado parcialmente por el Fondo de Investigación Sanitaria (FIS 04/0495), así como por la Generalitat de Catalunya (AMIC 10025). 


\section{INTRODUCCIÓN}

La expresión "migración internacional" comprende un amplio abanico de movimientos de población. Las motivaciones de estos movimientos y la condición jurídica de las personas emigrantes determinarán sus condiciones socioeconómicas y el tiempo de permanencia en el país de acogida ${ }^{1}$. Referente a las motivaciones, los procesos migratorios se pueden clasificar en función de su obligatoriedad/voluntariedad, corta/larga distancia o por razones económicas/no económicas ${ }^{2}$. Estos últimos son originados por los diferenciales de renta y calidad de vida entre países. Este tipo específico de migración es la respuesta que dan los individuos al conjunto de factores negativos en su región de origen para poder alcanzar un mayor estatus socioeconómico en el país de acogida.

En el momento que el inmigrante llega al país receptor las divergencias en las condiciones sociales y económicas entre países generan diferencias de acceso y utilización de los servicios sanitarios por parte de la población recién llegada. Las diferencias en la morbilidad atendida entre colectivos aparecerán en una segunda etapa, cuando las personas inmigrantes ya se han establecido en el país de acogida.

La llegada de los primeros inmigrantes a España generó gran cantidad de trabajos científicos que estudiaron dichas diferencias de morbilidad atendida entre la población inmigrante y la autóctona, centrándose básicamente en las enfermedades importadas del tipo exótico/tropical (aquéllas que el inmigrante trae de su país de origen y que son exclusivas de su región) ${ }^{3-}$ 5. Posteriormente, partiendo de la base de que las condiciones de vida repercuten sobre los niveles de salud y los patrones de morbilidad, surgieron estudios que pusieron énfasis en el hecho de que las que generan dichas diferencias en la morbilidad atendida ${ }^{6-15}$ son las enfermedades importadas del tipo cosmopolita (aquellas patologías derivadas de la situación socioeconómica del país de origen del inmigrante o de aquellas adquiridas $\mathrm{y} / \mathrm{o}$ agravadas en el país de acogida debido a la subsistencia del inmigrante en situaciones de precariedad laboral y social).

Actualmente, España cuenta con un $13,01 \%$ de población extranjera y Cataluña, una de las principales regiones receptoras dentro del estado, acoge el $20 \%$ de la población extranjera residente en el territorio nacional. Por su parte, Girona es la segunda provincia de destino de la población inmigrante dentro de Catalunya, pues acoge al 12,68\% de la inmigración catalana, porcentaje que representa el $20,8 \%$ del total de su población ${ }^{16,17}$. La Región Sanitaria de Girona (RSG) comprende siete sectores sanitarios que coinciden, prácticamente, con las siete comarcas que componen la provincia de Girona. En los últimos años el fenómeno de la inmigración y el envejecimiento de la población han supuesto un incremento de la población adscrita siendo de 709.520 habitantes $^{18}$ en enero de 2008. En su conjunto, la población residente en la RSG está compuesta por un $50,9 \%$ de hombres y un $49,1 \%$ de mujeres, con un $13,5 \%$ de individuos de más de 65 años. La población inmigrante procede principalmente de países suramericanos $(43 \%)$ y africanos $(26,4 \%)$. En menor medida, los inmigrantes llegan de Europa no comunitaria $(5,9 \%)$ o de Asia (5,3\%). La paridad en sexo $(50,3 \%$ de hombres y $49,7 \%$ de mujeres) y el envejecimiento de la población (16\% de población de más de 65 años) se mantiene cuando analizamos sólo la población autóctona. Por el contrario, cuando analizamos el colectivo inmigrante observamos una mayor presencia masculina $(55,2 \%$ de hombres frente a un $44,8 \%$ de mujeres) y una 
población mucho más joven, pues solo el $1,9 \%$ de individuos tiene más de 65 $\operatorname{años}^{17}$.

Este aumento de flujos de población procedente del extranjero (en concreto de países de baja renta) $)^{1,19}$, el progresivo envejecimiento de la población autóctona y el elevado índice de natalidad de esta población recién llegada $^{20}$ provocan un cambio en la estructura demográfica de nuestro país.

Para analizar las consecuencias de esta realidad cambiante es necesario disponer de una mayor información demográfica, socioeconómica, sanitaria y epidemiológica del colectivo inmigrante, con el fin de identificar sus necesidades reales y diseñar políticas sanitarias y de asignación de recursos dirigidas al conjunto de la población.

Pese a esta necesidad de información, las diversas fuentes disponibles presentan serias limitaciones que no permiten una visión completa de estos colectivos ${ }^{2}$ (social, económica, demográfica, etc.). Por un lado, los registros de población regularizada (censo de población, altas en la Seguridad Social o los datos del Ministerio del Interior) dejan fuera de su alcance toda la masa de población no regularizada. Por el otro, las fuentes de información de población no regular (Padrón Continuo de Habitantes, Encuesta de Población Activa, Tarjeta Individual Sanitaria o los datos del Instituto Nacional de Estadística) suelen contar con registros duplicados o problemas de cobertura y sesgo según el origen del inmigrante. Finalmente, muchos de estos registros no tienen en cuenta el país específico de nacimiento del inmigrante, con lo que dicho colectivo es tratado como un grupo homogéneo, si tener en cuenta los diferentes condicionantes sociales y económicos de los países de origen.
La importancia del fenómeno migratorio en nuestro país y la literatura más reciente sugieren la hipótesis de que existen características diferenciales en el colectivo de inmigrantes que determinan diferentes patrones de morbilidad y utilización de los servicios sanitarios. Aún así, no existe un único factor que explique dichas divergencias. Para algunos autores la clave reside en la falta de información de acceso al sistema sanitario ${ }^{21,22}$. Para otros, en las características sociales y demográficas del colectivo immigrante ${ }^{23-}$ 26. Otros inciden en los factores culturales (conocimientos, creencias o convicciones) $)^{25,27-29}$ y para algunos son esenciales los condicionantes económicos ${ }^{30}$.

Las características personales de cada inmigrante, determinadas por su origen, nos dan un perfil demográfico y cultural específico al que se le deben añadir los condicionantes sociales y económicos del país de acogida. Es la combinación de todos (o algunos de) estos factores ${ }^{31}$ los que determinaran la conducta en salud $^{32}$.

El objetivo de este trabajo es caracterizar la morbilidad y la utilización de los servicios sanitarios por parte del colectivo de inmigrantes, comparándolo con las características de las mismas variables en población autóctona, considerando el sexo, la edad, los condicionantes sociodemográficos y el origen del paciente.

\section{SUJETOS Y MÉTODOS}

Identificación de la población de estudio y selección de la muestra. En este estudio se considera como inmigrante a la "persona nacida en alguno de los países que forman parte de la clasificación de países en desarrollo agrupados por región" facilitada por el Programa de las Naciones Unidas para el Desarrollo (PNUD) $)^{33,34}$. 
Al descartarse la utilización de los registros de la Tarjeta de Información Sanitaria (TIS) por los mencionados problemas de duplicidad de registros, se partió de la información referente a la población usuaria de las Áreas Básicas de Salud (ABS) de Blanes, Banyoles, Girona 3, Olot, Roses, Salt, Santa Coloma de Farners y Sarrià de Ter. Su identificación se hizo mediante cuatro variables: lugar de nacimiento, año de llegada a Cataluña, lengua materna e idioma de contacto con el profesional médico. Dado que los campos referentes a estas variables, aunque no de obligada cumplimentación, preexistían en el programa de gestión de información y registro médico usado en atención primaria en la RSG (sistema denominado e-Cap) ${ }^{35}$, se creó un protocolo de recogida de dicha información y se distribuyó al conjunto de profesionales sanitarios de las ABS participantes en el proyecto para potenciar su cumplimentación.

Entre marzo y noviembre de 2006 los profesionales sanitarios recopilaron esta información de todos los usuarios atendidos, con el fin de obtener una referencia de población fiable de los usuarios de los servicios sanitarios para cada ABS. Durante dicho proceso de identificación desde el Instituto Catalán de la Salud (ICS) se ofreció información periódica sobre el volumen y calidad de la cumplimentación de los campos referentes a estas variables.

Esta primera fase permitió identificar al $73,39 \%$ de los usuarios inscritos en el Registro Central de Asegurados del 2004 para las 8 ABS participantes en el estudio (157.302 individuos), de entre los cuales se procedió a la selección de los participantes en el estudio. La aleatoriedad introducida en la selección de los usuarios identificados posibilitó asumir la representatividad en el contexto del estudio y permitió aceptar que la información sobre las variables que identifican a cada usuario no presentase sesgo frente al total de la población respecto a las variables de interés.

Con el objetivo de obtener una muestra representativa se clasificaron los usuarios identificados según su sexo, edad, ABS y país de origen. Esta estratificación generó una muestra de tamaño inabordable, por lo que se procedió a un conjunto de simplificaciones y agrupaciones: (1) se excluyeron los usuarios procedentes de Asia (por no ser un grupo suficientemente representativo en la RSG para realizar comparaciones con garantías) y los pacientes originarios de la Unión Europea antes del 2003, del Canadá, de Estados Unidos y de Australia (por no considerarse inmigrantes económicos); y (2) se rehusó a los niños por considerar necesario otro tipo de estudio que permita hacer comparaciones entre la población autóctona y la inmigrante de primera y segunda generación, y a las personas mayores de 65 años por no disponer de suficiente información de esta población de origen extranjero.

Dicho muestreo se realizó mediante estratificación no proporcional a fin de asegurar un tamaño de muestra suficiente por estrato y a cada ABS se le asignó una cuota proporcional al porcentaje de población identificada en cada centro. El plan de muestreo propuesto además de permitir hacer comparaciones fiables globales y desagregadas por sexo usando los pesos de elevación adecuados, posibilitó también realizar las comparaciones al nivel de estratificación establecido con fiabilidades que en ningún caso superaron el $10 \%$ de error trabajando a nivel de proporciones con el supuesto de máxima indeterminación y al 95\% de confianza. Así pues, se seleccionó una muestra de 900 personas (y una lista de substitución del mismo tamaño que la muestra) con un error muestral para el total de la muestra del 
$4,85 \%$ que estuvo formada por 300 usuarios autóctonos y 600 inmigrantes. La elevada movilidad geográfica de la población inmigrante imposibilitó la ejecución del volumen total de encuestas previstas. Por este motivo, los análisis que se presentan hacen referencia a una muestra real de 645 individuos, 268 usuarios autóctonos y 377 inmigrantes.

Elaboración del cuestionario. Paralelamente al proceso de identificación de la población de referencia se elaboró el cuestionario con el que se obtuvo la información, tomando como referente la Encuesta de Salud de Cataluña (ESCA). El cuestionario definitivo, consensuado entre todos los miembros participantes en el equipo, quedó dividido en cinco bloques: (1) situación personal del encuestado; (2) estado de salud el mismo; (3) estilos de vida; (4) salud mental y transculturalidad $^{36}$; y (5) relación con el país de origen (solo para inmigrantes), y se presentó al grupo de Mediadores Culturales del Hospital Dr. Josep Trueta de Girona y del Ámbito de Primaria de la RSG, con el fin de detectar posibles inconvenientes en la forma de plantear las preguntas y conseguir así una correcta comprensión por parte de los diferentes colectivos de inmigrantes.

La versión definitiva del cuestionario se trasladó a soporte informático, creando una aplicación usando el programa Mircrosoft Access $^{(R) 37}$. Esta aplicación se instaló desde el servidor central de los servicios informáticos del ICS en los ordenadores de las consultas médicas de los diferentes miembros del equipo investigador que administraron la encuesta. La recogida de información (entre enero y julio de 2007) se realizó automáticamente al responder el cuestionario y posibilitó la realización de un seguimiento preciso de la evolución del trabajo de campo con el fin de reconducir en tiempo real las posibles disfunciones que pudieran surgir.
Análisis estadístico. La información obtenida fue estudiada a través de un completo análisis descriptivo contrastando las diferencias entre los diversos colectivos de inmigrantes y la población autóctona. Cuando las variables cuya diferencia se comparaba eran cuantitativas se utilizó un contraste T-Student y en el caso de comparaciones de más de dos muestras (por ejemplo por origen del paciente) se realizó un contraste ANOVA. En la mayoría de los casos, al tratarse de variables cualitativas se utilizó un contraste no paramétrico ${ }^{-2}$ para comparar las proporciones.

$\mathrm{Al}$ trabajar con un diseño muestral estratificado no proporcional con población finita se utilizó el módulo de muestras complejas de SPSS v15 para el cálculo correcto de los errores estándar de los distintos estadísticos y para la correcta aplicación de los contrastes.

\section{RESULTADOS}

La información sociodemográfica y de estado de salud que se presenta hace referencia a 645 usuarios. Por el contrario, los datos referentes a la frecuentación de los servicios sanitarios se refieren a 575 de estos 645 usuarios, pues este fue el volumen de individuos sobre el que se pudo complementar la información sociodemográfica y de estado de salud obtenida en el cuestionario con datos referentes a frecuentación (número de contactos registrados con los servicios sanitarios de atención primaria durante el año 2006 y especialidad consultada en cada contacto para cada paciente) subministrados por el Servicio Catalán de la Salud (CatSalut).

Para los 575 usuarios se obtuvo un total de 6.682 visitas con una media de 11,62 y una desviación de 11,12 visitas por paciente y año. Las consultas más fre- 
cuentes se realizaron en los servicios de medicina general $(44,34 \%)$ y enfermería $(25,65 \%)$. Aunque en menor medida, fueron importantes también los servicios de extracciones $(5,81 \%)$ y atención continuada con el médico $(4,77 \%)$. Si bien fueron los ABS de Salt, Blanes, Roses y Banyoles los que presentaron un mayor porcentaje de población atendida, las ABS de Girona 3, Banyoles y Sarrià de Ter, fueron las que asistieron a pacientes con una mayor tasa de frecuentación (tabla 1).

De los 645 individuos encuestados el $61,7 \%$ fueron mujeres y el $38,3 \%$ hombres. En cuanto al origen, el 77,4\% de la muestra fue población autóctona respecto a un $22,6 \%$ de población inmigrante. Aunque un $44,4 \%$ del total de la muestra tenía entre 36 y 55 años, la población autóctona presentó un mayor envejecimiento que el colectivo inmigrante, tanto para el grupo femenino (45,8 años frente 35,8 años) como para el masculino (44,7 años frente 37,5 años).

Los resultados presentados en la tabla 2 recogen la comparación de distintas variables sociodemográficas entre el colectivo autóctono y el colectivo emigrante, así como la comparación entre los distintos orígenes de los usuarios entrevistados. Las diferencias estadísticamente significativas permitieron detectar una población inmigrante más joven $(53,3 \%$ frente al $21,6 \%$ de población mayor de 45 años), con un elevado contingente masculino $(34,9 \%$ de mujeres frente a un $50,1 \%$ de hombres), con una mayor situación de precariedad laboral $(5,6 \%$ frente al $9,4 \%$ de población en paro), con un menor nivel educativo $(17,4 \%$ frente a un $38 \%$ de población que no sabe leer ni escribir o con estudios primarios incompletos) y con unas peores condiciones de vivienda ( $85 \%$ frente a un $46,5 \%$ de población con vivienda de propiedad) que la población autóctona. Cuando se analizaron las diferencias entre colectivos, destacaron los usuarios africanos (subsaharianos y africanos del norte) con condiciones laborales (tasas de paro del $11,1 \%$ y $12,2 \%$, respectivamente), con niveles educativos $(70,6 \%$ y $48,8 \%$, respectivamente, de analfabetos o de individuos con estudios primarios incompletos) y con condiciones de vivienda (tasas de hogares de alquiler del $46 \%$ y $42 \%$, respectivamente) mucho más precarios que el resto de grupos de inmigrantes.

En la tabla 3 se realizan contrastes entre el origen de la persona entrevistada

Tabla 1

Población atendida y frecuencia de visitas por ABS

\begin{tabular}{|l|c|c|c|c|c|c|c|c|c|c|}
\hline \multicolumn{2}{|c|}{} & Girona 3 & Salt & Sarrià & $\begin{array}{c}\text { Sta. } \\
\text { Coloma }\end{array}$ & Banyoles & Blanes & Olot & Roses & Total \\
\hline $\begin{array}{l}\text { Población } \\
\text { encuestada }\end{array}$ & $\mathrm{N}$ & 38 & 145 & 51 & 15 & 101 & 120 & 63 & 112 & 645 \\
\cline { 2 - 13 } & $\%$ & $5,89 \%$ & $22,48 \%$ & $7,91 \%$ & $2,33 \%$ & $15,66 \%$ & $18,60 \%$ & $9,77 \%$ & $17,36 \%$ & $100 \%$ \\
\hline $\begin{array}{l}\text { Población con } \\
\text { frecuentación(*) }\end{array}$ & $\mathrm{N}$ & 31 & 127 & 45 & 15 & 99 & 101 & 57 & 100 & 575 \\
\cline { 2 - 13 }$y$ & $\%$ & $5,39 \%$ & $22,09 \%$ & $7,83 \%$ & $2,61 \%$ & $17,22 \%$ & $17,57 \%$ & $9,91 \%$ & $17,39 \%$ & $100 \%$ \\
\hline Visitas totales & 493 & 1386 & 617 & 124 & 1293 & 859 & 623 & 1288 & 6682 \\
\hline Visitas/paciente & 15,90 & 10,91 & 13,71 & 8,27 & 13,06 & 8,50 & 10,93 & 12,88 & 11,62 \\
\hline Desviación & 12,63 & 9,58 & 11,50 & 5,73 & 14,69 & 7,37 & 8,26 & 12,23 & 11,11 \\
\hline Mediana & 13 & 7 & 11 & 9 & 9 & 7 & 8 & 11 & 9 \\
\hline
\end{tabular}

(*) Volumen de población encuestada sobre la que se pudo vincular la información socioeconómica y de variables de salud con la frecuentación Sanitaria registrada en el e-Cap. 
Tabla 2

Distribución (\%) de las variables sociodemográficas en la población autóctona e inmigrante

\begin{tabular}{|c|c|c|c|c|c|c|c|c|}
\hline & $\begin{array}{c}\text { Autóctono } \\
\mathrm{n}=499\end{array}$ & $\begin{array}{c}\text { Inmigrante } \\
n=146\end{array}$ & España & $\begin{array}{c}\text { Europa } \\
\text { No com. } \\
9,5 \% \#\end{array}$ & $\begin{array}{c}\text { Sur } \\
\text { América } \\
25,3 \% \#\end{array}$ & $\begin{array}{c}\text { Centro } \\
\text { América } \\
6,3 \% \#\end{array}$ & $\begin{array}{c}\text { África } \\
\text { Subsahariana } \\
\text { 25,3\%\# }\end{array}$ & $\begin{array}{l}\text { África } \\
\text { Norte } \\
33,6 \% \#\end{array}$ \\
\hline \multicolumn{9}{|l|}{$\operatorname{Sexo}^{*, I}$} \\
\hline Hombre & 34,9 & 50,1 & 34,9 & 66,7 & 59,2 & 53,3 & 31,3 & 51,8 \\
\hline Mujer & 65,1 & 49,9 & 65,1 & 33,3 & 40,8 & 46,7 & 68,8 & 48,2 \\
\hline \multicolumn{9}{|l|}{ Edad $^{*}, \mathbf{I}$} \\
\hline $16-25$ & 10,6 & 16,1 & 10,6 & 23,7 & 12,5 & 16,7 & 14,1 & 18,1 \\
\hline $26-35$ & 16,9 & 30,4 & 16,9 & 29,0 & 27,5 & 30,0 & 34,4 & 30,1 \\
\hline $36-45$ & 19,2 & 31,8 & 19,2 & 26,9 & 27,5 & 36,7 & 35,9 & 32,5 \\
\hline $46-55$ & 23,9 & 17,0 & 23,9 & 17,2 & 22,5 & 13,3 & 14,1 & 15,7 \\
\hline 56-66 & 29,4 & 4,6 & 29,4 & 3,2 & 10,0 & 3,3 & 1,6 & 3,6 \\
\hline \multicolumn{9}{|l|}{ Estado civil } \\
\hline Soltero/a & 18,0 & 18,1 & 18,0 & 20,4 & 21,0 & 26,7 & 9,4 & 20,5 \\
\hline Casado/pareja & 72,2 & 75,8 & 72,2 & 68,8 & 68,1 & 63,6 & 89,1 & 75,9 \\
\hline Viudo/a & 2,7 & 1,7 & 2,7 & 2,2 & 4,2 & 0,0 & 1,6 & 0,0 \\
\hline Separado /divorciado & 7,1 & 4,4 & 7,1 & 8,6 & 6,7 & 10,0 & 0,0 & 3,6 \\
\hline \multicolumn{9}{|l|}{ Año llegada a España ${ }^{I}$} \\
\hline 1966-1985 & & 7,3 & & 0,0 & 6,1 & 3,6 & 7,9 & 10,7 \\
\hline 1986-1900 & & 9,8 & & 0,0 & 5,2 & 7,1 & 14,3 & 13,3 \\
\hline 1991-1995 & - & 9,4 & - & 6,7 & 4,3 & 0,0 & 15,9 & 10,7 \\
\hline 1996-2000 & & 30,9 & & 31,1 & 17,4 & 50,0 & 34,9 & 34,7 \\
\hline $2001-2006$ & & 42,6 & & 62,2 & 67,0 & 39,3 & 27,0 & 30,7 \\
\hline \multicolumn{9}{|l|}{ Nivel de estudios ${ }^{*}, I$} \\
\hline No sabe leer ni escribir & 2,4 & 9,5 & 2,4 & 2,2 & 0,9 & 0,0 & 14,5 & 15,9 \\
\hline Primarios incompletos & 15,0 & 28,5 & 15,0 & 3,3 & 7,1 & 6,9 & 58,1 & 32,9 \\
\hline Primarios completos & 37,4 & 17,1 & 37,4 & 16,5 & 14,2 & 20,7 & 22,6 & 14,6 \\
\hline Secundarios & 29,3 & 30,8 & 29,3 & 52,7 & 52,2 & 41,1 & 3,2 & 28,0 \\
\hline Diplomatura & 8,5 & 5,7 & 8,5 & 4,4 & 10,6 & 10,3 & 1,6 & 4,9 \\
\hline Licenciatura & 7,3 & 8,0 & 7,3 & 20,9 & 14,2 & 20,7 & 0,0 & 3,7 \\
\hline \multicolumn{9}{|l|}{ Sector ocupacional ${ }^{*}, \mathrm{I}$} \\
\hline Primario & 2,5 & 7,4 & 2,5 & 3,4 & 0,9 & 0,0 & 14,5 & 10,0 \\
\hline Secundario & 23,1 & 30,5 & 23,1 & 21,8 & 18,5 & 29,6 & 45,5 & 31,7 \\
\hline Terciario & 74,4 & 62,1 & 74,4 & 74,7 & 80,6 & 70,6 & 40,0 & 58,3 \\
\hline \multicolumn{9}{|l|}{ Situación laboral",I } \\
\hline Trabajo remunerado & 65,7 & 67,2 & 65,7 & 72,0 & 78,2 & 90,0 & 73,0 & 48,8 \\
\hline Paro & 5,6 & 9,4 & 5,6 & 8,6 & 5,9 & 3,3 & 11,1 & 12,2 \\
\hline Tareas del hogar & 11,6 & 16,4 & 11,6 & 10,8 & 9,2 & 6,7 & 11,1 & 29,3 \\
\hline Estudiante & 2,8 & 3,6 & 2,8 & 7,5 & 5,0 & 0,0 & 16 & 3,7 \\
\hline Jubilado & 10,4 & 0,4 & 10,4 & 0,0 & 0,0 & 0,0 & 0,0 & 1,2 \\
\hline Incapacitado & 4,0 & 3,0 & 4,0 & 1,1 & 1,7 & 0,0 & 3,2 & 4,9 \\
\hline \multicolumn{9}{|l|}{ Contrato laboral ${ }^{*}, \mathbf{I}$} \\
\hline Funcionario & 8,0 & 0,5 & 8,0 & 0,0 & 0,0 & 0,0 & 1,7 & 0,0 \\
\hline Asalariado indefinido & 55,9 & 42,9 & 55,9 & 34,1 & 41,4 & 59,3 & 41,4 & 45,2 \\
\hline Asalariado temporal & 16,8 & 37,9 & 16,8 & 42,4 & 36,0 & 25,9 & 44,8 & 33,9 \\
\hline Sin contrato & 4,6 & 8,5 & 4,6 & 20,0 & 9,9 & 7,4 & 6,9 & 4,8 \\
\hline Autónomo (con/sin trabajadores) & 10,9 & 6,8 & 10,9 & 3,5 & 9,9 & 7,4 & 3,4 & 8,0 \\
\hline Otras situaciones & 3,8 & 3,5 & 3,8 & 0,0 & 2,7 & 0,0 & 1,7 & 8,1 \\
\hline \multicolumn{9}{|l|}{ Propiedad hogar ${ }^{*}, \mathbf{I}$} \\
\hline Propiedad & 85,0 & 46,5 & 85,0 & 48,4 & 30,5 & 70,0 & 50,0 & 50,6 \\
\hline Alquiler & 8,3 & 48,9 & 8,3 & 46,2 & 66,1 & 30,0 & 46,9 & 42,2 \\
\hline Familiar, amigos, otros & 6,7 & 4,5 & 6,7 & 5,4 & 3,4 & 0,0 & 3,2 & 7,2 \\
\hline \multicolumn{9}{|l|}{ Hogar habitual",I } \\
\hline Unifamiliar & 90,9 & 84,3 & 90,9 & 92,5 & 92,4 & 96,7 & 81,2 & 75,9 \\
\hline Plurifamiliar & 8,7 & 15,2 & 8,7 & 6,5 & 5,9 & 3,3 & 18,8 & 24,1 \\
\hline Lugar de trabajo & 0,0 & 0,3 & 0,0 & 1,1 & 0,8 & 0,0 & 0,0 & 0,0 \\
\hline Otros & 0,4 & 0,2 & 0,4 & 0,0 & 0,8 & 0,0 & 0,0 & 0,0 \\
\hline
\end{tabular}


Tabla 2 (continuación)

Distribución (\%) de las variables sociodemográficas en la población autóctona e inmigrante

\begin{tabular}{|c|c|c|c|c|c|c|c|c|}
\hline & $\begin{array}{c}\text { Autóctono } \\
\mathrm{n}=499\end{array}$ & $\begin{array}{c}\text { Inmigrante } \\
n=146\end{array}$ & España & $\begin{array}{c}\text { Europa } \\
\text { No com. } \\
9,5 \% \#\end{array}$ & $\begin{array}{c}\text { Sur } \\
\text { América } \\
25,3 \% \#\end{array}$ & $\begin{array}{c}\text { Centro } \\
\text { América } \\
\text { 6,3\%\# }\end{array}$ & $\begin{array}{c}\text { África } \\
\text { Subsahariana } \\
\text { 25,3\%\# }\end{array}$ & $\begin{array}{c}\text { África } \\
\text { Norte } \\
33,6 \% \#\end{array}$ \\
\hline Calefacción en el hogar ${ }^{*}, \mathbf{I}$ & & & & & & & & \\
\hline Sí & 89,8 & 57,1 & 89,8 & 74,2 & 67,2 & 73,3 & 54,7 & 43,4 \\
\hline No & 10,2 & 42,9 & 10,2 & 25,8 & 32,8 & 26,7 & 45,3 & 56,6 \\
\hline
\end{tabular}

* $\mathrm{p}<0,05$

** $\mathrm{p}<0,10$ para el contraste de diferencias de proporciones entre autóctonos e inmigrantes

I $\mathrm{p}<0,05$

II $\mathrm{p}<0,10$ para el contraste de diferencias de proporciones entre los diferentes orígenes específicos del usuario

\# Porcentaje de población inmigrante según región de procedencia sobre el total de inmigrantes analizados.

Tabla 3

Distribución (\%) de las variables de salud en la población autóctona e inmigrante

\begin{tabular}{|c|c|c|c|c|c|c|c|c|}
\hline & $\begin{array}{c}\text { Autóctono } \\
n=499\end{array}$ & $\begin{array}{c}\text { Inmigrante } \\
n=146\end{array}$ & España & $\begin{array}{l}\text { Europa } \\
\text { No com } \\
9,5 \% \#\end{array}$ & $\begin{array}{l}\text { Sur } \\
\text { América } \\
25,3 \% \#\end{array}$ & $\begin{array}{l}\text { Centro } \\
\text { América } \\
6,3 \% \#\end{array}$ & $\begin{array}{c}\text { África } \\
\text { Subsahariana } \\
\mathbf{2 5 , 3 \% \#}\end{array}$ & $\begin{array}{l}\text { África } \\
\text { Norte } \\
33,6 \% \#\end{array}$ \\
\hline $\begin{array}{l}\text { Salud percibida }{ }^{*} \text {,I } \\
\text { Excelente } \\
\text { Muy buena } \\
\text { Buena } \\
\text { Regular } \\
\text { Mala }\end{array}$ & $\begin{array}{r}4,0 \\
17,5 \\
50,4 \\
22,6 \\
5,6\end{array}$ & $\begin{array}{r}4,4 \\
28,0 \\
43,9 \\
20,2 \\
3,4\end{array}$ & $\begin{array}{r}4,0 \\
17,5 \\
50,4 \\
22,6 \\
5,6\end{array}$ & $\begin{array}{r}4,5 \\
24,7 \\
46,1 \\
23,6 \\
1,1\end{array}$ & $\begin{array}{r}5,3 \\
36,0 \\
36,8 \\
19,3 \\
2,6\end{array}$ & $\begin{array}{r}3,3 \\
20,0 \\
40,0 \\
33,3 \\
3,3\end{array}$ & $\begin{array}{r}6,3 \\
37,5 \\
43,8 \\
10,9 \\
1,6\end{array}$ & $\begin{array}{r}2,5 \\
17,3 \\
49,4 \\
24,7 \\
6,2\end{array}$ \\
\hline $\begin{array}{l}\text { Visita profesionales médicos últimos } \\
30 \text { días",I } \\
\text { Sí } \\
\text { No }\end{array}$ & $\begin{array}{l}61,2 \\
38,8\end{array}$ & $\begin{array}{l}50,1 \\
49,9\end{array}$ & $\begin{array}{l}61,2 \\
38,8\end{array}$ & $\begin{array}{l}39,1 \\
60,9\end{array}$ & $\begin{array}{l}39,2 \\
60,8\end{array}$ & $\begin{array}{l}70,0 \\
30,0\end{array}$ & $\begin{array}{l}50,0 \\
50,0\end{array}$ & $\begin{array}{l}57,8 \\
42,2\end{array}$ \\
\hline $\begin{array}{l}\text { Problema de salud que motivó la } \\
\text { visita* }^{*} \\
\text { Dolor } \\
\text { Infecciones } \\
\text { Controles/Recetas/Vacunas } \\
\text { Alergia } \\
\text { Traumatismos } \\
\text { Otros }\end{array}$ & $\begin{array}{r}13,5 \\
18,4 \\
40,6 \\
5,6 \\
2,8 \\
19,1\end{array}$ & $\begin{array}{r}27,3 \\
13,6 \\
22,7 \\
6,1 \\
3,0 \\
27,3\end{array}$ & $\begin{array}{r}13,6 \\
18,4 \\
40,8 \\
5,4 \\
2,7 \\
19,0\end{array}$ & $\begin{array}{r}20,0 \\
20,0 \\
40,0 \\
0,0 \\
0,0 \\
20,0\end{array}$ & $\begin{array}{r}15,4 \\
15,4 \\
30,8 \\
0,0 \\
7,7 \\
30,8\end{array}$ & $\begin{array}{c}33,3 \\
16,7 \\
16,7 \\
0,0 \\
16,7 \\
16,7\end{array}$ & $\begin{array}{r}22,2 \\
16,7 \\
22,2 \\
5,6 \\
0,0 \\
33,3\end{array}$ & $\begin{array}{r}37,5 \\
8,3 \\
20,8 \\
8,3 \\
0,0 \\
25,0\end{array}$ \\
\hline $\begin{array}{l}\text { Sufrió problemas de salud y no } \\
\text { acudió al médico } \\
\text { Sí } \\
\text { No }\end{array}$ & $\begin{array}{l}14,1 \\
85,9\end{array}$ & $\begin{array}{l}16,1 \\
83,9\end{array}$ & $\begin{array}{l}14,1 \\
85,9\end{array}$ & $\begin{array}{l}16,1 \\
83,9\end{array}$ & $\begin{array}{l}17,3 \\
82,7\end{array}$ & $\begin{array}{l}13,8 \\
86,2\end{array}$ & $\begin{array}{r}8,9 \\
91,1\end{array}$ & $\begin{array}{l}20,8 \\
79,2\end{array}$ \\
\hline $\begin{array}{l}\text { Motivos por los que no acudió al } \\
\text { médico pese a los problemas de salud } \\
\text { Pérdida horas de trabajo } \\
\text { Motivo insuficientemente grave } \\
\text { Largas horas de espera } \\
\text { Otros motivos }\end{array}$ & $\begin{array}{r}16,7 \\
60,0 \\
20,0 \\
3,3\end{array}$ & $\begin{array}{r}21,3 \\
65,4 \\
6,3 \\
7,0\end{array}$ & $\begin{array}{r}16,7 \\
60,0 \\
20,0 \\
3,3\end{array}$ & $\begin{array}{r}42,9 \\
50,0 \\
7,1 \\
0,0\end{array}$ & $\begin{array}{r}16,7 \\
77,8 \\
0,0 \\
5,6\end{array}$ & $\begin{array}{r}75,0 \\
25,0 \\
0,0 \\
0,0\end{array}$ & $\begin{array}{r}20,0 \\
80,0 \\
0,0 \\
0,0\end{array}$ & $\begin{array}{l}12,5 \\
62,5 \\
12,5 \\
12,5\end{array}$ \\
\hline $\begin{array}{l}\text { Sufre de trastornos crónicosa, I } \\
\text { Sí } \\
\text { No }\end{array}$ & $\begin{array}{l}51,4 \\
48,6\end{array}$ & $\begin{array}{l}29,6 \\
70,4\end{array}$ & $\begin{array}{l}51,4 \\
48,6\end{array}$ & $\begin{array}{l}26,1 \\
73,9\end{array}$ & $\begin{array}{l}30,8 \\
69,2\end{array}$ & $\begin{array}{l}26,7 \\
73,3\end{array}$ & $\begin{array}{l}28,1 \\
71,9\end{array}$ & $\begin{array}{l}31,3 \\
68,7\end{array}$ \\
\hline $\begin{array}{l}\text { Tipo de trastorno crónico } \\
\text { Hipertensión }{ }^{\mathrm{a}, \mathrm{I}} \\
\text { Colesterol }^{\mathrm{a}, \mathrm{I}} \\
\text { Diabetes }^{\mathrm{b}} \\
\text { Alergia }^{\mathrm{a}, \mathrm{II}} \\
\text { Enfermedad pulmonar }^{\mathrm{a}, \mathrm{II}} \\
\text { Enfermedad cardíaca } \\
\text { Enfermedad digestivaa } \\
\text { EI }\end{array}$ & $\begin{array}{r}16,5 \\
9,4 \\
5,9 \\
1,7 \\
7,1 \\
3,9 \\
7,5\end{array}$ & $\begin{array}{l}7,7 \\
3,9 \\
3,1 \\
3,5 \\
2,1 \\
1,8 \\
3,2\end{array}$ & $\begin{array}{r}16,5 \\
9,4 \\
5,9 \\
1,7 \\
7,1 \\
3,9 \\
7,5\end{array}$ & $\begin{array}{l}5,4 \\
6,5 \\
2,2 \\
4,3 \\
2,2 \\
2,2 \\
3,2\end{array}$ & $\begin{array}{r}10,8 \\
3,3 \\
5,0 \\
4,2 \\
5,8 \\
3,3 \\
6,7\end{array}$ & $\begin{array}{l}6,7 \\
0,0 \\
0,0 \\
0,0 \\
0,0 \\
0,0 \\
0,0\end{array}$ & $\begin{array}{r}10,9 \\
1,6 \\
1,6 \\
3,1 \\
0,0 \\
1,6 \\
1,6\end{array}$ & $\begin{array}{l}3,6 \\
6,0 \\
3,6 \\
3,6 \\
1,2 \\
1,2 \\
2,4\end{array}$ \\
\hline
\end{tabular}


Tabla 3 (continuación)

Distribución (\%) de las variables de salud en la población autóctona e inmigrante

\begin{tabular}{|c|c|c|c|c|c|c|c|c|}
\hline & $\begin{array}{c}\text { Autóctono } \\
\mathrm{n}=499\end{array}$ & $\begin{array}{c}\text { Inmigrante } \\
n=146\end{array}$ & España & $\begin{array}{l}\text { Europa } \\
\text { No com } \\
9,5 \% \#\end{array}$ & $\begin{array}{l}\text { Sur } \\
\text { América } \\
25,3 \% \#\end{array}$ & $\begin{array}{l}\text { Centro } \\
\text { América } \\
6,3 \% \#\end{array}$ & $\begin{array}{c}\text { África } \\
\text { Subsahariana } \\
\mathbf{2 5 , 3 \% \#}\end{array}$ & $\begin{array}{l}\text { África } \\
\text { Norte } \\
33,6 \% \#\end{array}$ \\
\hline $\begin{array}{l}\text { Uso de medicamentos los } 2 \text { días } \\
\text { previos a la entrevista",I } \\
\text { Sí } \\
\text { No }\end{array}$ & $\begin{array}{l}66,7 \\
33,3 \\
\end{array}$ & $\begin{array}{l}50,0 \\
50,0 \\
\end{array}$ & $\begin{array}{l}66,7 \\
33,3 \\
\end{array}$ & $\begin{array}{l}47,3 \\
52,7\end{array}$ & $\begin{array}{l}55,8 \\
44,2\end{array}$ & $\begin{array}{l}66,7 \\
33,3\end{array}$ & $\begin{array}{l}50,0 \\
50,0\end{array}$ & $\begin{array}{l}43,4 \\
56,6\end{array}$ \\
\hline $\begin{array}{l}\text { Tipo de medicamento usado } \\
\text { Aspirina o antiinflamatorio } \\
\text { Tranquilizante o sedante }{ }^{*}, \mathrm{I} \\
\text { Antidepresivo }^{*, I} \\
\text { Medicamento para asma }{ }^{\mathrm{I}} \\
\text { Medicamento para la alergia } \\
\text { Medicamento para la tos o resfriado } \\
\text { Antibiótico } \\
\text { Medicamento para el corazón } \\
\text { Medicamento para tensión arterial } \\
\text { Medicamento para colesterol }{ }^{*}, \mathrm{I} \\
\text { Medicamento para la diabetes }^{* *}\end{array}$ & $\begin{array}{r}29,0 \\
10,2 \\
11,8 \\
5,5 \\
3,9 \\
2,4 \\
3,1 \\
2,7 \\
16,1 \\
7,5 \\
5,5\end{array}$ & $\begin{array}{r}25,9 \\
3,2 \\
4,0 \\
2,7 \\
2,1 \\
1,8 \\
2,1 \\
1,6 \\
6,9 \\
3,2 \\
2,7\end{array}$ & $\begin{array}{r}29,0 \\
10,2 \\
11,8 \\
5,5 \\
3,9 \\
2,4 \\
3,1 \\
2,7 \\
16,1 \\
7,5 \\
5,5\end{array}$ & $\begin{array}{r}20,4 \\
2,2 \\
3,2 \\
2,2 \\
3,3 \\
1,1 \\
2,2 \\
1,1 \\
5,4 \\
3,2 \\
2,2\end{array}$ & $\begin{array}{r}25,0 \\
5,8 \\
8,3 \\
4,2 \\
3,3 \\
0,8 \\
1,7 \\
1,7 \\
9,2 \\
5,0 \\
3,3 \\
\end{array}$ & $\begin{array}{r}46,7 \\
3,3 \\
3,3 \\
3,3 \\
0,0 \\
3,3 \\
6,7 \\
3,3 \\
6,7 \\
0,0 \\
0,0\end{array}$ & $\begin{array}{r}28,2 \\
0,0 \\
1,6 \\
1,6 \\
1,6 \\
4,7 \\
1,6 \\
1,6 \\
9,4 \\
1,6 \\
1,6 \\
\end{array}$ & $\begin{array}{r}20,5 \\
2,4 \\
0,0 \\
1,2 \\
0,0 \\
1,2 \\
1,2 \\
1,2 \\
2,4 \\
2,4 \\
3,6\end{array}$ \\
\hline $\begin{array}{l}\text { Consumo de sustancias para dormir }{ }^{*}, \mathbf{I} \\
\text { Sí } \\
\text { No }\end{array}$ & $\begin{array}{l}15,9 \\
84,1\end{array}$ & $\begin{array}{r}4,7 \\
95,3\end{array}$ & $\begin{array}{l}15,9 \\
84,1\end{array}$ & $\begin{array}{r}3,2 \\
96,8\end{array}$ & $\begin{array}{l}10,9 \\
89,1\end{array}$ & $\begin{array}{r}6,7 \\
93,3\end{array}$ & $\begin{array}{r}3,2 \\
96,8\end{array}$ & $\begin{array}{r}1,2 \\
98,8\end{array}$ \\
\hline $\begin{array}{l}\text { Realización exámenes preventivos }{ }^{*}, \mathbf{I} \\
\text { Sí } \\
\text { No }\end{array}$ & $\begin{array}{l}76,8 \\
23,2\end{array}$ & $\begin{array}{l}53,5 \\
46,5\end{array}$ & $\begin{array}{l}76,8 \\
23,2\end{array}$ & $\begin{array}{l}58,1 \\
41,9\end{array}$ & $\begin{array}{l}65,5 \\
34,5\end{array}$ & $\begin{array}{l}53,3 \\
46,7\end{array}$ & $\begin{array}{l}38,1 \\
61,9\end{array}$ & $\begin{array}{l}54,9 \\
45,1\end{array}$ \\
\hline $\begin{array}{l}\text { Motivos del examen preventivo }{ }^{\mathbf{I}} \\
\text { Voluntario } \\
\text { Exigencias de la empresa }\end{array}$ & $\begin{array}{l}75,5 \\
24,5\end{array}$ & $\begin{array}{l}70,2 \\
28,9\end{array}$ & $\begin{array}{l}75,5 \\
24,5\end{array}$ & $\begin{array}{l}34,0 \\
66,0\end{array}$ & $\begin{array}{l}13,0 \\
87,0\end{array}$ & $\begin{array}{l}31,3 \\
68,8\end{array}$ & $\begin{array}{l}54,2 \\
45,8\end{array}$ & $\begin{array}{l}30,2 \\
69,8\end{array}$ \\
\hline $\begin{array}{l}\text { Visita a SSI antes de viajar }{ }^{*}, \mathbf{I} \\
\text { Sí } \\
\text { No } \\
\text { No viaja }\end{array}$ & $\begin{array}{r}22,5 \\
8,4 \\
69,1\end{array}$ & $\begin{array}{l}29,2 \\
27,7 \\
43,1\end{array}$ & $\begin{array}{r}22,5 \\
8,4 \\
69,1\end{array}$ & $\begin{array}{l}10,9 \\
21,7 \\
67,4\end{array}$ & $\begin{array}{l}23,3 \\
18,1 \\
58,6\end{array}$ & $\begin{array}{l}10,3 \\
34,5 \\
55,2\end{array}$ & $\begin{array}{l}66,7 \\
19,0 \\
14,3\end{array}$ & $\begin{array}{l}13,6 \\
42,0 \\
44,4\end{array}$ \\
\hline $\begin{array}{l}\text { Vacunas antes de viajar }{ }^{*}, \mathbf{I} \\
\text { Sí } \\
\text { No } \\
\text { No viaja }\end{array}$ & $\begin{array}{l}64,3 \\
14,3 \\
21,4\end{array}$ & $\begin{array}{r}56,4 \\
39,2 \\
4,4\end{array}$ & $\begin{array}{l}64,3 \\
14,3 \\
21,4\end{array}$ & $\begin{array}{l}55,2 \\
27,6 \\
17,2\end{array}$ & $\begin{array}{l}58,3 \\
29,2 \\
12,5\end{array}$ & $\begin{array}{r}23,1 \\
69,2 \\
7,7\end{array}$ & $\begin{array}{r}82,7 \\
17,3 \\
0,0\end{array}$ & $\begin{array}{r}29,5 \\
68,2 \\
2,3\end{array}$ \\
\hline $\begin{array}{l}\text { Conocimiento métodos de } \\
\text { planificación familiar }{ }^{*, I} \\
\text { Sí } \\
\text { No }\end{array}$ & $\begin{array}{r}94,8 \\
5,2\end{array}$ & $\begin{array}{l}79,7 \\
20,3\end{array}$ & $\begin{array}{r}94,8 \\
5,2\end{array}$ & $\begin{array}{r}95,6 \\
4,4\end{array}$ & $\begin{array}{r}92,0 \\
8,0\end{array}$ & $\begin{array}{l}85,7 \\
14,3\end{array}$ & $\begin{array}{l}66,1 \\
33,9\end{array}$ & $\begin{array}{l}75,0 \\
25,0\end{array}$ \\
\hline $\begin{array}{l}\text { Permiso cultural para uso métodos } \\
\text { planificación Familiar",I } \\
\text { Sí } \\
\text { No }\end{array}$ & $\begin{array}{r}97,7 \\
2,3\end{array}$ & $\begin{array}{l}87,6 \\
12,4\end{array}$ & $\begin{array}{r}97,7 \\
2,3\end{array}$ & $\begin{array}{r}97,6 \\
2,4\end{array}$ & $\begin{array}{r}96,0 \\
4,0\end{array}$ & $\begin{array}{r}95,5 \\
4,5\end{array}$ & $\begin{array}{l}84,2 \\
15,8\end{array}$ & $\begin{array}{l}76,4 \\
23,6\end{array}$ \\
\hline $\begin{array}{l}\text { Utiliza métodos de planificación } \\
\text { familiar } \\
\text { Sí } \\
\text { No }\end{array}$ & $\begin{array}{l}46,4 \\
53,6\end{array}$ & $\begin{array}{l}53,0 \\
47,0\end{array}$ & $\begin{array}{l}46,4 \\
53,6\end{array}$ & $\begin{array}{l}54,8 \\
45,2\end{array}$ & $\begin{array}{l}59,0 \\
41,0\end{array}$ & $\begin{array}{l}54,5 \\
45,5\end{array}$ & $\begin{array}{l}47,4 \\
52,6\end{array}$ & $\begin{array}{l}50,0 \\
50,0\end{array}$ \\
\hline $\begin{array}{l}\text { Tipo de métodos de planificación } \\
\text { familiar usados }{ }^{*, I} \\
\text { Preservativo } \\
\text { DIU } \\
\text { Métodos definitivos } \\
\text { Píldora } \\
\text { Métodos tradicionales }\end{array}$ & $\begin{array}{r}41,2 \\
7,4 \\
32,4 \\
19,1 \\
0,0\end{array}$ & $\begin{array}{r}43,9 \\
8,7 \\
9,6 \\
32,1 \\
5,6\end{array}$ & $\begin{array}{r}41,2 \\
7,4 \\
32,4 \\
19,1 \\
0,0\end{array}$ & $\begin{array}{r}45,7 \\
5,7 \\
5,7 \\
31,4 \\
11,4\end{array}$ & $\begin{array}{r}48,6 \\
8,1 \\
18,9 \\
18,9 \\
5,4\end{array}$ & $\begin{array}{r}42,9 \\
14,3 \\
0,0 \\
28,6 \\
14,3\end{array}$ & $\begin{array}{r}80,0 \\
10,0 \\
10,0 \\
0,0 \\
0,0\end{array}$ & $\begin{array}{r}22,7 \\
9,1 \\
4,5 \\
59,1 \\
4,5\end{array}$ \\
\hline
\end{tabular}

* $\mathrm{p}<0,05$

** $\mathrm{p}<0,10$ para el contraste de diferencias de proporciones entre autóctonos e inmigrantes

I $\mathrm{p}<0,05$

II $\mathrm{p}<0,10$ para el contraste de diferencias de proporciones entre los diferentes orígenes específicos del usuario.

\# Porcentaje de población inmigrante según región de procedencia sobre el total de inmigrantes analizados. 
Tabla 4a

Frecuentación, según variables sociodemográficas,

de los servicios sanitarios en la población autóctona e inmigrante

\begin{tabular}{|c|c|c|c|c|c|c|c|c|c|}
\hline & \multirow{2}{*}{\multicolumn{3}{|c|}{ Conjunto de la muestra }} & \multicolumn{6}{|c|}{ Según origen } \\
\hline & & & & \multicolumn{3}{|c|}{ Autóctonos } & \multicolumn{3}{|c|}{ Inmigrantes } \\
\hline & $\mathbf{x}$ & $\sigma$ & $\mathrm{Me}$ & $\mathbf{x}$ & $\sigma$ & Me & $\mathbf{x}$ & $\sigma$ & Me \\
\hline $\begin{array}{r}\text { Edad }^{*} \\
16-25 \\
26-35 \\
36-45 \\
46-55 \\
56-66\end{array}$ & $\begin{array}{r}9,7 \\
9,2 \\
10,6 \\
15,4 \\
14,2\end{array}$ & $\begin{array}{r}9,7 \\
8,4 \\
9,5 \\
14,8 \\
11,2\end{array}$ & $\begin{array}{r}6 \\
8 \\
7 \\
11 \\
11\end{array}$ & $\begin{array}{r}9,5 \\
8,6 \\
10,3 \\
15,1 \\
14,2\end{array}$ & $\begin{array}{r}10,0 \\
6,3 \\
9,7 \\
14,3 \\
11,3\end{array}$ & $\begin{array}{r}6 \\
8 \\
7 \\
10 \\
11\end{array}$ & $\begin{array}{l}10,0 \\
10,6 \\
11,2 \\
16,9 \\
12,1\end{array}$ & $\begin{array}{r}9,1 \\
11,6 \\
9,1 \\
17,0 \\
7,3\end{array}$ & $\begin{array}{r}8 \\
7 \\
8 \\
12 \\
11\end{array}$ \\
\hline $\begin{array}{l}\text { Nivel de estudios* } \\
\text { No sabe leer ni escribir }{ }^{\mathrm{I}} \\
\text { Primarios incompletos } \\
\text { Primarios completos } \\
\text { Secundarios } \\
\text { Diplomatura }{ }^{\mathrm{II}} \\
\text { Licenciatura }\end{array}$ & $\begin{array}{r}25,5 \\
14,3 \\
11,7 \\
11,2 \\
9,3 \\
9,0\end{array}$ & $\begin{array}{r}21,7 \\
13,1 \\
9,1 \\
10,8 \\
7,6 \\
9,1\end{array}$ & $\begin{array}{r}18 \\
10 \\
9 \\
7 \\
8 \\
8\end{array}$ & $\begin{array}{r}36,2 \\
15,5 \\
11,8 \\
11,4 \\
8,5 \\
8,5\end{array}$ & $\begin{array}{r}26,7 \\
12,7 \\
9,3 \\
11,2 \\
6,9 \\
5,6\end{array}$ & $\begin{array}{r}39 \\
13 \\
9 \\
7 \\
7 \\
8\end{array}$ & $\begin{array}{l}16,9 \\
11,9 \\
10,3 \\
10,5 \\
13,6 \\
10,9\end{array}$ & $\begin{array}{r}12,1 \\
13,6 \\
7,4 \\
9,5 \\
10,2 \\
16,3\end{array}$ & $\begin{array}{r}14 \\
7 \\
9 \\
8 \\
12 \\
7\end{array}$ \\
\hline $\begin{array}{l}\text { Situación laboral* }^{*} \\
\text { Trabajo remunerado } \\
\text { Paro } \\
\text { Tareas del hogar } \\
\text { Estudiante } \\
\text { Jubilado } \\
\text { Incapacitado }\end{array}$ & $\begin{array}{c}11,1 \\
19,7 \\
11,5 \\
10,2 \\
14,7 \\
19,0\end{array}$ & $\begin{array}{r}10,6 \\
19,8 \\
7,7 \\
8,5 \\
8,3 \\
17,4\end{array}$ & $\begin{array}{r}8 \\
14 \\
9 \\
9 \\
14 \\
12\end{array}$ & $\begin{array}{l}11,1 \\
22,9 \\
11,3 \\
11,0 \\
14,8 \\
16,9\end{array}$ & $\begin{array}{r}10,5 \\
22,6 \\
7,0 \\
9,2 \\
8,3 \\
14,4\end{array}$ & $\begin{array}{r}8 \\
17 \\
9 \\
11 \\
14 \\
12\end{array}$ & $\begin{array}{r}11,1 \\
13,0 \\
12,0 \\
8,0 \\
10,0 \\
27,7\end{array}$ & $\begin{array}{r}11,1 \\
10,0 \\
9,6 \\
6,6 \\
0,0 \\
27,6\end{array}$ & $\begin{array}{r}8 \\
10 \\
10 \\
9 \\
10 \\
14\end{array}$ \\
\hline $\begin{array}{l}\text { Jornada laboral }^{* *} \\
\text { Completa partida } \\
\text { Media } \\
\text { Nocturna }^{\mathrm{I}} \\
\text { Turnos variables } \\
\text { Intensiva } \\
\text { Otras }\end{array}$ & $\begin{array}{r}10,2 \\
13,3 \\
6,0 \\
11,3 \\
13,6 \\
11,1\end{array}$ & $\begin{array}{r}9,9 \\
13,5 \\
5,0 \\
8,9 \\
13,5 \\
3,8\end{array}$ & $\begin{array}{r}7 \\
10 \\
5 \\
9 \\
9 \\
11\end{array}$ & $\begin{array}{c}10,1 \\
13,6 \\
2,0 \\
11,3 \\
14,0 \\
11,5\end{array}$ & $\begin{array}{r}9,0 \\
14,4 \\
1,2 \\
9,0 \\
13,9 \\
3,4\end{array}$ & $\begin{array}{r}7 \\
10 \\
2 \\
9 \\
10 \\
12\end{array}$ & $\begin{array}{r}10,8 \\
12,6 \\
9,9 \\
11,0 \\
10,0 \\
7,4\end{array}$ & $\begin{array}{r}12,5 \\
11,2 \\
3,9 \\
8,6 \\
9,6 \\
-\end{array}$ & $\begin{array}{r}7 \\
11 \\
11 \\
9 \\
8 \\
-\end{array}$ \\
\hline $\begin{array}{l}\text { Propiedad del hogar } \\
\text { En propiedad } \\
\text { En alquiler } \\
\text { Familiares, amigos, otros }\end{array}$ & $\begin{array}{l}12,0 \\
13,1 \\
12,1\end{array}$ & $\begin{array}{r}10,5 \\
15,4 \\
8,9\end{array}$ & $\begin{array}{r}9 \\
9 \\
10\end{array}$ & $\begin{array}{l}12,1 \\
14,1 \\
11,9\end{array}$ & $\begin{array}{r}10,7 \\
18,2 \\
8,4\end{array}$ & $\begin{array}{r}9 \\
9 \\
10\end{array}$ & $\begin{array}{l}11,0 \\
12,4 \\
13,7\end{array}$ & $\begin{array}{r}9,3 \\
13,5 \\
12,5\end{array}$ & $\begin{array}{r}8 \\
9 \\
12\end{array}$ \\
\hline
\end{tabular}

* pvalor $<0,05$

** pvalor $<0,1$ en el contraste de diferencias de medias dentro de las categorías de la variable para el conjunto de la muestra.

I pvalor $<0,05$

II pvalor $<0,1$ en el contraste de diferencias de medias entre autóctonos e inmigrantes para cada categoría de a variable.

y variables de salud. Los contrastes significativos permiten observar que la población autóctona realiza un mayor número de visitas $(61,2 \%$ frente a un $50,1 \%)$, consume mayor cantidad de medicamentos $(66,7 \%$ frente el $50 \%$ de fármacos y $15,9 \%$ frente un $4,7 \%$ de sustancias para dormir), padece más trastornos crónicos (51,4\% versus el $29,6 \%)$, realiza más prácticas preventivas $(76,8 \%$ versus $53,5 \%)$ y tiene un mayor conocimiento de los métodos de planificación familiar (94,8\% frente a un $79,7 \%)$ que la población inmigrante. Este perfil sanitario de la población autóctona se ve claramente influenciado por sus características demográficas, pues dichas características sanitarias se acentúan significativamente con la edad del usuario. Por otra parte, el tipo de trastorno crónico padecido muestra diferencias significativas en función del origen específico del paciente, siendo los Sur y Centro americanos los que más habitualmente padecieron hipertensión $(10,8 \%$ y $10,9 \%)$ y los Europeos No Comunitarios fueron más propensos a padecer colesterol $(6,5 \%)$.

En la tabla 4 se muestra la frecuentación de los servicios sanitarios para el 
Tabla $4 \mathbf{b}$

Frecuentación y variables sociodemográficas

en la población autóctona e inmigrante, según sexo

\begin{tabular}{|c|c|c|c|c|c|c|c|c|c|c|c|c|}
\hline & \multicolumn{6}{|c|}{ Hombre } & \multicolumn{6}{|c|}{ Mujer } \\
\hline & \multicolumn{3}{|c|}{ Autóctono } & \multicolumn{3}{|c|}{ Inmigrante } & \multicolumn{3}{|c|}{ Autóctono } & \multicolumn{3}{|c|}{ Inmigrante } \\
\hline & $\overline{\mathbf{x}}$ & $\sigma$ & Me & $\overline{\mathbf{x}}$ & $\sigma$ & $\mathrm{Me}$ & $\overline{\mathbf{x}}$ & $\sigma$ & Me & $\overline{\mathbf{x}}$ & $\sigma$ & Me \\
\hline $\begin{array}{l}\text { Edad } \\
\begin{array}{l}16-25^{c} \\
26-35 \\
36-45 \\
46-55 \\
56-66\end{array}\end{array}$ & $\begin{array}{r}5,5 \\
7,2 \\
11,0 \\
14,6 \\
14,0\end{array}$ & $\begin{array}{r}4,9 \\
4,1 \\
11,9 \\
9,9 \\
14,7\end{array}$ & $\begin{array}{r}4 \\
6 \\
7 \\
17 \\
9\end{array}$ & $\begin{array}{r}8,4 \\
8,8 \\
11,3 \\
16,6 \\
13,4\end{array}$ & $\begin{array}{r}9,4 \\
12,7 \\
10,8 \\
17,7 \\
6,5\end{array}$ & $\begin{array}{r}6 \\
5 \\
7 \\
12 \\
12\end{array}$ & $\begin{array}{r}12,7 \\
9,3 \\
9,9 \\
15,3 \\
14,4\end{array}$ & $\begin{array}{c}11,8 \\
7,0 \\
8,2 \\
15,7 \\
9,3\end{array}$ & $\begin{array}{r}7 \\
9 \\
7 \\
10 \\
13\end{array}$ & $\begin{array}{l}11,5 \\
12,4 \\
11,1 \\
17,3 \\
10,1\end{array}$ & $\begin{array}{r}9,1 \\
10,2 \\
7,6 \\
17,0 \\
10,2\end{array}$ & $\begin{array}{r}11 \\
10 \\
9 \\
13 \\
10\end{array}$ \\
\hline $\begin{array}{l}\text { Nivel de estudios } \\
\text { No sabe leer ni escribir }{ }^{\mathrm{a}, \mathrm{c}} \\
\text { Primarios incompletos } \\
\text { Primarios completos }^{\mathrm{c}} \\
\text { Secundarios }{ }^{\mathrm{C}} \\
\text { Diplomatura } \\
\text { Licenciatura }\end{array}$ & $\begin{array}{r}74,0 \\
18,2 \\
9,7 \\
7,7 \\
10,0 \\
10,2\end{array}$ & $\begin{array}{r}0,0 \\
11,8 \\
8,2 \\
6,2 \\
10,2 \\
5,8\end{array}$ & $\begin{array}{c}74 \\
16 \\
7 \\
7 \\
6 \\
12\end{array}$ & $\begin{array}{r}17,5 \\
11,4 \\
8,9 \\
10,1 \\
18,0 \\
6,5\end{array}$ & $\begin{array}{r}16,9 \\
15,0 \\
8,4 \\
10,7 \\
19,5 \\
5,3\end{array}$ & $\begin{array}{r}17 \\
7 \\
7 \\
7 \\
27 \\
6\end{array}$ & $\begin{array}{r}26,8 \\
14,3 \\
12,7 \\
14,6 \\
7,9 \\
7,8\end{array}$ & $\begin{array}{c}20,1 \\
13,1 \\
9,5 \\
13,4 \\
5,5 \\
5,5\end{array}$ & $\begin{array}{r}24 \\
10 \\
11 \\
10 \\
8 \\
7\end{array}$ & $\begin{array}{l}16,6 \\
12,6 \\
12,1 \\
10,9 \\
11,7 \\
15,0\end{array}$ & $\begin{array}{r}10,9 \\
11,6 \\
6,0 \\
8,5 \\
5,5 \\
22,4\end{array}$ & $\begin{array}{r}15 \\
8 \\
12 \\
9\end{array}$ \\
\hline $\begin{array}{l}\text { Situación laboral } \\
\text { Trabajo remunerado } \\
\text { Paro } \\
\text { Tareas del hogar } \\
\text { Estudiante } \\
\text { Jubilado } \\
\text { Incapacitado }\end{array}$ & $\begin{array}{r}9,4 \\
38,5 \\
17,0 \\
3,5 \\
14,8 \\
15,2\end{array}$ & $\begin{array}{r}8,4 \\
41,1 \\
0,0 \\
2,9 \\
9,4 \\
11,8\end{array}$ & $\begin{array}{c}7 \\
39 \\
17 \\
4 \\
14 \\
12\end{array}$ & $\begin{array}{r}9,8 \\
12,2 \\
4,7 \\
9,3 \\
10,0 \\
30,2\end{array}$ & $\begin{array}{r}10,6 \\
10,2 \\
- \\
8,7 \\
0,0 \\
29,4\end{array}$ & $\begin{array}{c}7 \\
10 \\
- \\
11 \\
10 \\
29\end{array}$ & $\begin{array}{l}12,2 \\
19,8 \\
11,1 \\
14,8 \\
14,8 \\
19,0\end{array}$ & $\begin{array}{c}11,5 \\
17,0 \\
7,1 \\
9,0 \\
7,4 \\
17,8\end{array}$ & $\begin{array}{r}9 \\
17 \\
9 \\
18 \\
14 \\
14\end{array}$ & $\begin{array}{r}12,8 \\
14,4 \\
12,2 \\
6,5 \\
- \\
12,0\end{array}$ & $\begin{array}{c}11,6 \\
10,8 \\
9,6 \\
6,2 \\
- \\
0,0\end{array}$ & $\begin{array}{c}10 \\
12 \\
10 \\
10 \\
- \\
12\end{array}$ \\
\hline $\begin{array}{l}\text { Propiedad del hogar } \\
\text { En propiedad } \\
\text { En alquiler }^{\mathrm{a}, \mathrm{c}} \\
\text { Familiares, amigos, otros }^{\mathrm{c}}\end{array}$ & $\begin{array}{r}9,7 \\
23,7 \\
14,4\end{array}$ & $\begin{array}{r}7,6 \\
28,9 \\
9,7\end{array}$ & $\begin{array}{c}7 \\
8 \\
12\end{array}$ & $\begin{array}{r}9,5 \\
12,5 \\
11,3\end{array}$ & $\begin{array}{r}9,1 \\
15,0 \\
15,3\end{array}$ & $\begin{array}{l}7 \\
8 \\
6\end{array}$ & $\begin{array}{r}13,3 \\
9,7 \\
9,7\end{array}$ & $\begin{array}{c}11,8 \\
7,7 \\
6,5\end{array}$ & $\begin{array}{r}10 \\
9 \\
10\end{array}$ & $\begin{array}{l}12,3 \\
12,3 \\
17,6\end{array}$ & $\begin{array}{r}9,5 \\
11,8 \\
8,7\end{array}$ & $\begin{array}{l}10 \\
10 \\
21\end{array}$ \\
\hline
\end{tabular}

pvalor $<0,05$

pvalor $<0,1$ en el contraste de diferencias de medias entre autóctonos e inmigrantes dentro del colectivo masculino.

pvalor $<0,05$

B pvalor $<0,1$ en el contraste de diferencias de medias entre autóctonos e inmigrantes dentro del colectivo femenino.

c pvalor $<0,05$

C pvalor $<0,1$ en el contraste de diferencias de medias dentro del colectivo autóctono, entre hombres y mujeres.

d pvalor $<0,05$

D pvalor $<0,1$ en el contraste de diferencias de medias dentro del colectivo inmigrante, entre hombres y mujeres.

conjunto de la muestra de 575 usuarios en función de las variables sociodemográficas y de salud. En ella se muestra el resultado de los contrastes para el total de la muestra y distinguiendo entre el origen de los usuarios (tablas 4a y 4c) y los contrastes que evalúan las diferencias entre hombres y mujeres tanto dentro como entre procedencias (tablas $4 \mathrm{~b} \mathrm{y}$ $4 d$ ). Se hace evidente que a peores niveles de formación (25,5 visitas/paciente cuando no se sabe leer ni escribir frente 9 cuando se poseen estudios de licenciatura) y mayor precariedad laboral $(19,7$ visitas/paciente en situación de paro frente 11,1 en situación de trabajo remunerado) mayor es la frecuentación de los servicios de salud, independientemente del origen del paciente. Cabe destacar que a iguales condiciones sociodemográficas, mientras dentro del colectivo inmigrante los hombres y las mujeres presentan tasas de frecuentación no estadísticamente diferentes entre ellos, dentro del colectivo autóctono las variables sociodemográficas son factores relevantes en cuanto a las diferencias de frecuentación entre hombres y mujeres en el sentido que a peores condiciones sociodemográficas los hombres son más frecuentadores (74 frente 26,8 visitas medias al año cuando no se sabe leer ni escribir; 23,7 frente 9,7 visitas medias al año cuando se vive de alquiler). Referente a las variables de salud, una peor salud real y/o percibida influye en una mayor 
Tabla 4c

Frecuentación, según variables de salud,

de los servicios sanitarios en la población autóctona e inmigrante

\begin{tabular}{|c|c|c|c|c|c|c|c|c|c|}
\hline & \multirow{2}{*}{\multicolumn{3}{|c|}{ Conjunto de la muestra }} & \multicolumn{6}{|c|}{ Según origen } \\
\hline & & & & \multicolumn{3}{|c|}{ Autóctonos } & \multicolumn{3}{|c|}{ Inmigrantes } \\
\hline & $\overline{\mathbf{x}}$ & $\sigma$ & Me & $\overline{\mathbf{x}}$ & $\sigma$ & Me & $\overline{\mathbf{x}}$ & $\sigma$ & $\mathrm{Me}$ \\
\hline Salud percibida* & & & & & & & & & \\
\hline Excelente & 5,1 & 4,0 & 4 & 4,4 & 3,0 & 4 & 6,9 & 6,2 & 7 \\
\hline Muy buena $a^{I I}$ & 8,0 & 8,1 & 6 & 7,1 & 6,6 & 6 & 10,0 & 10,8 & 7 \\
\hline Buena & 11,7 & 9,9 & 9 & 11,6 & 9,5 & 9 & 11,9 & 11,4 & 9 \\
\hline Regular & 14,7 & 12,5 & 12 & 15,1 & 13,0 & 13 & 12,7 & 9,9 & 11 \\
\hline Mala & 27,0 & 17,4 & 21 & 27,1 & 16,5 & 22 & 25,9 & 24,8 & 21 \\
\hline $\begin{array}{l}\text { Visita por profesionales médicos los } \\
\text { últimos } 30 \text { días" }^{*}\end{array}$ & & & & & & & & & \\
\hline Sín & 14,5 & 12,7 & 12 & 14,7 & 12,6 & 12 & 13,4 & 13,1 & 10 \\
\hline No & 8,6 & 7,7 & 7 & 8,1 & 6,9 & 6 & 10,2 & 9,6 & 7 \\
\hline Sufre de trastornos crónicos* & & & & & & & & & \\
\hline Sí & 15,6 & 12,9 & 13 & 15,7 & 12,8 & 13 & 14,9 & 14,0 & 12 \\
\hline NoII & 9,1 & 8,6 & 7 & 8,5 & 7,9 & 7 & 10,5 & 10,2 & 8 \\
\hline $\begin{array}{l}\text { Uso de medicamentos los dos días } \\
\text { previos a la entrevista* }\end{array}$ & & & & & & & & & \\
\hline Sí & 14,5 & 11,9 & 12 & 14,8 & 12,0 & 12 & 13,0 & 11,4 & 11 \\
\hline $\mathrm{No}^{\mathrm{I}}$ & 8,0 & 8,9 & 5 & 6,8 & 7,1 & 5 & 10,7 & 11,7 & 7 \\
\hline Consumo de substancias para dormir* & & & & & & & & & \\
\hline Sí & 19,8 & 15,5 & 15 & 20,1 & 15,9 & 15 & 17,0 & 11,5 & 16 \\
\hline No & 11,0 & 10,1 & 9 & 10,9 & 9,6 & 9 & 11,6 & 11,6 & 8 \\
\hline Realización de exámenes preventivos" & & & & & & & & & \\
\hline Sí & 12,8 & 11,6 & 9 & 12,9 & 11,4 & 9 & 12,4 & 12,3 & 10 \\
\hline No & 10,6 & 10,7 & 7 & 10,3 & 10,7 & 6 & 11,2 & 10,8 & 8 \\
\hline $\begin{array}{l}\text { Conocimiento de los métodos de } \\
\text { planificación familiar* }\end{array}$ & & & & & & & & & \\
\hline Sí & 11,6 & 10,6 & 9 & 11,6 & 10,2 & 9 & 11,6 & 12,1 & 8 \\
\hline No & 17,1 & 18,1 & 12 & 20,7 & 23,3 & 11 & 13,8 & 10,8 & 12 \\
\hline $\begin{array}{l}\text { Utilización de los métodos de } \\
\text { planificación familiar* }\end{array}$ & & & & & & & & & \\
\hline $\mathrm{Si}^{\mathrm{II}}$ & 9,9 & 9,8 & 7 & 9,3 & 8,7 & 6 & 12,3 & 13,0 & 8 \\
\hline No & 13,3 & 11,3 & 10 & 13,8 & 11,2 & 11 & 11,3 & 11,9 & 9 \\
\hline
\end{tabular}

pvalor $<0,05$

** pvalor $<0,1$ en el contraste de diferencias de medias dentro de las categorías de la variable para el conjunto de la muestra.

pvalor $<0,05$

II pvalor $<0,1$ en el contraste de diferencias de medias entre autóctonos e inmigrantes para cada categoría de a variable.

frecuentación de los servicios de salud mientras que un mayor conocimiento de métodos de planificación familiar y su utilización, favorece un menor uso de los servicios médicos, independientemente del origen específico del paciente. Las principales divergencias de género se dan, de nuevo, en el colectivo autóctono. La frecuentación es mayor en las mujeres que en los hombres autóctonos cuando la percepción de salud es peor, cuando el motivo de visita son los controles/receptas/vacunas o el dolor. Contrariamente, la frecuentación es mayor en los hombres autóctonos que en las mujeres del mismo grupo, cuando se sufre diabetes mellitus, enfermedades pulmonares o neoplasia. Referente a las diferencias entre colectivos autóctonos e inmigrantes para el grupo de mujeres se observa una mayor frecuentación en el colectivo autóctono cuando peor se considera la propia salud (27 frente 14,9 visitas medias al año) mientras que esta es mayor en las mujeres inmigrantes cuando no se conocen los métodos de planificación familiar (14,2 frente 16,5 visitas/paciente y año). 
Tabla 4d

Frecuentación y variables de salud

en la población autóctona e inmigrante, según sexo

\begin{tabular}{|c|c|c|c|c|c|c|c|c|c|c|c|c|}
\hline & \multicolumn{6}{|c|}{ Hombre } & \multicolumn{6}{|c|}{ Mujer } \\
\hline & \multicolumn{3}{|c|}{ Autóctono } & \multicolumn{3}{|c|}{ Inmigrante } & \multicolumn{3}{|c|}{ Autóctono } & \multicolumn{3}{|c|}{ Inmigrante } \\
\hline & $\overline{\mathbf{x}}$ & $\sigma$ & $\mathrm{Me}$ & $\overline{\mathbf{x}}$ & $\sigma$ & $\mathrm{Me}$ & $\overline{\mathbf{x}}$ & $\sigma$ & $\mathrm{Me}$ & $\overline{\mathbf{x}}$ & $\sigma$ & Me \\
\hline $\begin{array}{l}\text { Salud percibida } \\
\text { Excelente } \\
\text { Muy buena } \\
\text { Buena } \\
\text { R,D } \\
\text { Regular }^{\mathrm{C}} \\
\text { Mala }^{\mathrm{C}}\end{array}$ & $\begin{array}{r}4,3 \\
8,3 \\
8,8 \\
19,2 \\
20,7\end{array}$ & $\begin{array}{r}2,1 \\
6,7 \\
6,9 \\
19,7 \\
9,6\end{array}$ & $\begin{array}{r}4 \\
7 \\
7 \\
13 \\
20\end{array}$ & $\begin{array}{r}7,0 \\
10,3 \\
9,0 \\
14,9 \\
31,6\end{array}$ & $\begin{array}{r}8,9 \\
12,8 \\
8,5 \\
13,3 \\
33,4\end{array}$ & $\begin{array}{r}8 \\
6 \\
7 \\
11 \\
32\end{array}$ & $\begin{array}{r}4,6 \\
6,6 \\
13,3 \\
13,7 \\
32\end{array}$ & $\begin{array}{r}3,7 \\
6,5 \\
10,4 \\
9,5 \\
19,1\end{array}$ & $\begin{array}{r}4 \\
5 \\
10 \\
13 \\
29\end{array}$ & $\begin{array}{r}6,9 \\
9,6 \\
14,7 \\
11,3 \\
18,2\end{array}$ & $\begin{array}{r}4,9 \\
7,1 \\
13,1 \\
7,2 \\
13,5\end{array}$ & $\begin{array}{r}7 \\
8 \\
11 \\
11 \\
23\end{array}$ \\
\hline $\begin{array}{l}\text { Problema de salud que } \\
\text { motivó la visita } \\
\text { Dolor } \\
\text { Infecciones } \\
\text { Controles/Recetas/Vacunas }{ }^{\mathrm{a}, \mathrm{c}} \\
\text { Alergia } \\
\text { Traumatismos } \\
\text { Otros }\end{array}$ & $\begin{array}{r}8,0 \\
13,1 \\
12,0 \\
9,0 \\
8,0 \\
13,9\end{array}$ & $\begin{array}{r}9,0 \\
22,0 \\
7,0 \\
0,0 \\
4,6 \\
9,5\end{array}$ & $\begin{array}{r}5 \\
7 \\
12 \\
9 \\
8 \\
15\end{array}$ & $\begin{array}{r}12,5 \\
7,6 \\
19,5 \\
9,3 \\
9,0 \\
12,2\end{array}$ & $\begin{array}{r}10,8 \\
6,0 \\
17,9 \\
12,6 \\
- \\
9,7\end{array}$ & $\begin{array}{c}10 \\
10 \\
14 \\
10 \\
- \\
12\end{array}$ & $\begin{array}{c}13,6 \\
12,5 \\
16,3 \\
21,9 \\
30, \\
11,9\end{array}$ & $\begin{array}{r}11,1 \\
8,2 \\
11,5 \\
19,0 \\
11,6 \\
12,9\end{array}$ & $\begin{array}{r}10 \\
12 \\
14 \\
20 \\
30 \\
7\end{array}$ & $\begin{array}{r}10,9 \\
10,7 \\
14,1 \\
28,9 \\
8,8 \\
12,0\end{array}$ & $\begin{array}{r}9,7 \\
5,1 \\
18,2 \\
10,8 \\
19,2 \\
11,5\end{array}$ & $\begin{array}{r}11 \\
10 \\
10 \\
32 \\
15 \\
9\end{array}$ \\
\hline $\begin{array}{l}\text { Sufre de trastornos crónicos } \\
\text { Sí } \\
\mathrm{No}^{\mathrm{a}, \mathrm{C}}\end{array}$ & $\begin{array}{r}14,8 \\
7,1\end{array}$ & $\begin{array}{r}13,8 \\
5,4\end{array}$ & $\begin{array}{r}12 \\
6\end{array}$ & $\begin{array}{l}13,6 \\
10,4\end{array}$ & $\begin{array}{l}16,0 \\
11,4\end{array}$ & $\begin{array}{r}10 \\
7\end{array}$ & $\begin{array}{r}16,1 \\
9,2\end{array}$ & $\begin{array}{r}12,2 \\
8,8\end{array}$ & $\begin{array}{r}13 \\
7\end{array}$ & $\begin{array}{l}15,9 \\
10,7\end{array}$ & $\begin{array}{r}12,7 \\
8,7\end{array}$ & $\begin{array}{r}14 \\
8\end{array}$ \\
\hline $\begin{array}{l}\text { Tipo de trastorno crónico } \\
\text { (solo casos afirmativos) } \\
\text { Hipertensión } \\
\text { Colesterol } \\
\text { Diabetes }{ }^{\mathrm{C}} \\
\text { Enfermedad pulmonar }{ }^{\mathrm{C}} \\
\text { Neoplásia }^{\mathrm{C}}\end{array}$ & $\begin{array}{l}18,3 \\
14,9 \\
24,1 \\
37,3 \\
43,0\end{array}$ & $\begin{array}{l}12,3 \\
13,3 \\
21,5 \\
28,8 \\
35,9\end{array}$ & $\begin{array}{l}15 \\
11 \\
23 \\
24 \\
43\end{array}$ & $\begin{array}{r}12,4 \\
16,3 \\
26,9 \\
8,9 \\
3,0\end{array}$ & $\begin{array}{r}11,5 \\
18,9 \\
26,5 \\
24,1 \\
0,0\end{array}$ & $\begin{array}{r}11 \\
14 \\
37 \\
15 \\
3\end{array}$ & $\begin{array}{r}15,1 \\
15,1 \\
12,4 \\
21,4 \\
6,5\end{array}$ & $\begin{array}{r}10,8 \\
10,9 \\
4,9 \\
17,3 \\
4,1\end{array}$ & $\begin{array}{r}12 \\
12 \\
13 \\
17 \\
7\end{array}$ & $\begin{array}{r}17,6 \\
19,5 \\
26,0 \\
24,5 \\
8,4\end{array}$ & $\begin{array}{r}9,0 \\
33,0 \\
33,8 \\
43,1 \\
-\end{array}$ & $\begin{array}{c}18 \\
15 \\
20 \\
20 \\
-\end{array}$ \\
\hline $\begin{array}{l}\text { Conocimiento de los métodos } \\
\text { de planificación familiar } \\
\mathrm{Si}^{\mathrm{c}} \\
\mathrm{No}^{\mathrm{b}, \mathrm{c}}\end{array}$ & $\begin{array}{l}10,1 \\
40,0\end{array}$ & $\begin{array}{r}8,8 \\
27,4\end{array}$ & $\begin{array}{r}7 \\
31\end{array}$ & $\begin{array}{l}11,2 \\
11,7\end{array}$ & $\begin{array}{l}13,4 \\
12,5\end{array}$ & $\begin{array}{l}7 \\
9\end{array}$ & $\begin{array}{l}12,3 \\
14,2\end{array}$ & $\begin{array}{l}10,7 \\
18,4\end{array}$ & $\begin{array}{l}9 \\
9\end{array}$ & $\begin{array}{l}11,8 \\
16,5\end{array}$ & $\begin{array}{r}11,0 \\
8,0\end{array}$ & $\begin{array}{r}9 \\
16\end{array}$ \\
\hline
\end{tabular}

a pvalor $<0,05$ A pvalor $<0,1$ en el contraste de diferencias de medias entre autóctonos e inmigrantes dentro del colectivo masculino

b pvalor $<0,05{ }^{\mathrm{B}}$ pvalor $<0,1$ en el contraste de diferencias de medias entre autóctonos e inmigrantes dentro del colectivo femenino.

c pvalor $<0,05{ }^{C}$ pvalor $<0,1$ en el contraste de diferencias de medias entre hombres y mujeres dentro del colectivo autóctono.

d pvalor $<0,05$ p pvalor $<0,1$ en el contraste de diferencias de medias entre hombres y mujeres dentro del colectivo inmigrante.

\section{DISCUSIÓN}

Los resultados obtenidos en el análisis presentado permiten identificar factores que inciden en la utilización de los servicios de salud públicos. Así, las divergencias en la frecuentación de los servicios de atención primaria según el origen geográfico de los pacientes no pudieron atribuirse sólo al origen sino que fueron debidas a las variables sociodemográficas del participante. De este modo se detectaron como factores determinantes de la utilización de los servicios de atención primaria el nivel formativo, la situación laboral, la salud real y la percibida, las prácticas preventivas en salud sexual y reproductiva, la edad y el tiempo de residencia en el país de acogida.
En primer lugar, con las cautelas que supone el tamaño muestral utilizado, fuera cual fuese el lugar de nacimiento del usuario, una peor situación laboral y un menor nivel formativo supuso una mayor frecuentación $^{38,39}$. Por otra parte, tanto para pacientes autóctonos como para los inmigrantes, una peor salud real y/o percibida, supone una mayor utilización de los servicios sanitarios ${ }^{40,41}$. En tercer lugar, un mayor conocimiento de los métodos de planificación familiar propició una menor frecuentación a los servicios de atención primaria. Finalmente, otro factor que se manifestó relevante fue el hecho de que a mayor edad mayor era el uso de los servicios sanitarios públicos y que los inmigrantes llegados más recientemente pre- 
sentaban unas tasas de frecuentación menores que los que llevan más tiempo en el país de acogida. Si tenemos en cuenta que la población inmigrante es un colectivo aún joven que llega al país receptor con unos niveles de salud más que aceptables $^{7,15}$ y que en el ámbito de la salud en nuestro país la inmigración es un fenómeno reciente 26,39 se hace evidente pensar que la población inmigrante no usa más los servicios públicos de salud que la población autóctona por el mero hecho de ser inmigrante sino que son los factores sociodemográficos y físicos los que determinan los patrones de utilización ${ }^{42}$. Así, pese a que a su llegada el inmigrante es un individuo sano ${ }^{43,44}$ a medida que reside en el país de acogida, además de hacerse mayor, llega a conocer y adaptarse al sistema público de salud, de modo que su frecuencia de utilización aumenta ${ }^{45}$.

Además de detectar los factores incidentes en la utilización de los servicios de atención primaria, las comparaciones realizadas entre las poblaciones inmigrantes y autóctonas permitieron constatar la importancia de la heterogeneidad dentro del colectivo inmigrante, pues muchas de las divergencias no salieron a la luz comparando la población autóctona con todos los inmigrantes sino que se observaron cuando se tuvo en cuenta el origen específico del inmigrante ${ }^{46-51}$. De este modo los pacientes procedentes de África, tanto los individuos subsaharianos como los africanos del norte, presentaron reiteradamente una peor situación social y laboral. Aún así, una vez controladas dichas variables sociodemográficas, la utilización de los servicios sanitarios se mostró sin diferencias estadísticamente significativas entre los diferentes colectivos.

En definitiva, los resultados obtenidos nos permiten deducir que existe un amplio abanico de factores que influyen en la utilización de los servicios sanitarios de atención primaria. Se hace evidente pues que no es posible atribuir únicamente al origen del inmigrante un determinado patrón de comportamiento en cuanto al uso de los servicios de salud. Es la combinación de elementos sociales (formación, ocupación, cultura y creencias) y demográficos (edad) inherentes a cada individuo lo que permite explicar dicha utilización.

Finalmente, en relación a la perspectiva de género, observamos que las divergencias en cuanto a frecuentación, aunque también están presentes en los distintos colectivos de inmigrantes, son mucho más evidentes entre hombres y mujeres autóctonos debido posiblemente a los diferentes roles de género que desempeñan unos y otros ${ }^{52}$.

Somos conscientes que el presente artículo muestra los datos referentes a usuarios de $8 \mathrm{ABS}$ de la RSG. Por lo tanto, cabría tener cierta cautela con la limitación geográfica de los resultados y, por tanto, con el hecho de que éstos podrían no ser extrapolables al conjunto de la población inmigrante del territorio español, debido a las divergentes características socioeconómicas de los grupos de inmigrantes. Asimismo, la información que se presenta hace referencia a los individuos que han sido usuarios de los servicios sanitarios de atención primaria durante el año 2006. Por lo tanto, las conclusiones sólo son aplicables a los individuos que usan los servicios de salud pero no al conjunto de la población residente en la RSG. En tercer lugar, la muestra analizada adolece de la falta de presencia de individuos asiáticos pues este colectivo tuvo una representación de un $1 \%$ en la fase de identificación de la población usuaria. Finalmente, debe recordarse que la recogida de datos en la fase de identificación de la población, pese a disponer de un protocolo específico, fue un trabajo totalmente voluntario por parte de los profesionales sanitarios (médicos, enfermeros y personal administrativo) de las ABS que formaban parte del proyecto. 
Estas consideraciones nos han llevado a plantear este proyecto a instituciones gubernamentales, con el fin de estandarizar dicho protocolo en todos los centros de salud. De este modo, sería posible obtener información identificativa fidedigna de todos los usuarios de los servicios sanitarios (independientemente de su situación administrativa) que se podría vincular a datos socioeconómicos a partir de la administración de cuestionarios a un mayor tamaño muestral.

\section{AGRADECIMIENTOS}

Agradecemos a los profesionales sanitarios de las Áreas Básicas de Salud de Banyoles, Blanes, Girona 3, Olot, Roses, Salt, Santa Coloma de Farners y Sarrià de Ter, su implicación y esfuerzo en el proceso de identificación de la población y recogida de datos. Agradecemos también a las personas que han revisado el trabajo de forma anónima sus comentarios que han ayudado a mejorar este trabajo. También agradecemos a Iñaki Galán sus sugerencias a las versiones preliminares del artículo. Y a la editora de la Revista Española de Salud Pública las que realizó tras recibir la primera versión del trabajo.

\section{BIBLIOGRAFÍA}

1. VII Conferencia Iberoamericana de ministras y ministros de salud. Uruguay; Septiembre 2006. Uruguay: Ministerio de Uruguay, Organización panamericana de la salud, Organización Mundial de la Salud; 2006.

2. Berra S, Elorza Rocard JM, Bartomeu N, Hausmann S, Serra-Sutton V, Rajmil L. Necessitats en salud i utilització dels serveis sanitaris en la població immigrant a Catalunya; Revisió exhaustiva de la literatura científica. Barcelona: Agència d'Avaluació de Tecnología i Recerca Mèdiques; 2004. Anales de medicina: 87.

3. Colectivo IOE. Las estadísticas sobre la inmigración: información limitada. Índice, Revista de estadística y sociedad. 2004; 3: 10-11.
4. Farias Huanqui P, editores. Manual de atención primaria a la población inmigrante. Madrid: Artur, SA; 2001.

5. Balanzó X, Bada JL, González C.A. La atención sanitaria en la población africana residente en la comarca del Maresme (Barcelona). Rev San Hig Publ. 1984; 58:769-78.

6. Jauma Pou RM, Vinamata B. Morbilidad atendida de la población inmigrante africana en un centro de salud. Aten Primaria. 1994;13(6):283-9.

7. Serra-Sutton V, Hausmann S, Bartomeu N, Berra S, Elorza-Ricart JM, Rajmil L. Experiències de recerca i polítiques de salut relacionades amb immigració en altres països europeus. El cas dels Països Baixos, el Regne Unit i Suïssa. Informe Tècnic, Barcelona: Agència d'Avaluació de Tecnologia i Recerca Mèdiques (AATRM); 2004.

8. Singh GK, Siahpush M. Ethnic-immigrant differentials in health behaviours, morbidity and causespecific mortality in the United States: an analysis of two national data bases. Human Biology (San Antonio). 2002; 74(1):83-109.

9. Shawn M, Dorling D, Brimblecombe N. Mortality and migration in Britain, first results from the British Household Panel Survey. Soc Sci Med. 1999; 49(7):981-988.

10. Westering R, Rosén M. Avoidable mortality among immigrants in Sweden. Eur J Public Health. 2002; 12(4):279-286.

11. Alonso Moreno FJ, Garcia Bajo MC, Lougedo Calderon MJ, Comas Samper JM, Garcia Palencia M, Lopez de Castro F, et al. Prevalencia de infección tuberculosa en las personas inmigrantes del área de salud de Toledo. Revista Española de Salud Pública. 2004; 78:593-600.

12. Balanzó X. Enfermedades importadas y medicina de la inmigración. Aten Primaria. 1997. 8(7):527528 .

13. Vall Combelles O, García-Algar O. Inmigración y salud. An Pediatr (Barc). 2004; 60: 1-2

14. Larios MJ, Nadal M. L'estat de la immigració a Catalunya. Anuari 2005. Barcelona: Fundació Jaume Bofill; 2006.

15. Balanzó X, Faixedas MT, Guayta R. Els immigrants i la seva salut. Quaderns de bona praxi. 2003; 16(3):5-13.

16. Fundación BBVA. La población de Girona. Madrid: Fundación BBVA; 2007 
17. Instituto Nacional de Estadística. Revisión del Padrón Municipal 2008. Datos por municipios. Disponible en http://www.ine.es

18. Servei Català de la Salut. Memòria d'activitat 2007. Disponible en http://www10.gencat.cat/catsalut

19. Ministerio de trabajo e inmigración: Observatorio permanente de la inmigración. Anuario estadístico de inmigración 2007. Disponible en: http://extrajeros.mtas.es

20. Jansà JM, García de Olalla P. Salut i immigració: noves realitats $\mathrm{i}$ nous reptes. En: Borrell $\mathrm{C}$, Benach J. Les desigualtats en salut a Catalunya. Barcelona: Ed. Mediterrània; 2003.

21. Saura RM, Suñol R, Vallejo P, Lahoz S, Atxotequi J, Monouari M. El marco sanitario y el entorno psicosocial de la población inmigrante magrebí en Catalunya. Gac Sanit. 2008; 22(6):547-54.

22. Ponsonby. Comisión de migraciones, refugiados y demografía.Condiciones sanitarias de los inmigrantes y refugiados en Europa. Estrasburgo: Asamblea Parlamentaria; 2000.

23. Brimbecomble N, Dorling D, Shaw M. Migration and geographical inequalities in health in Britain. Soc Sci Med. 2000; 50(6):861-878.

24. Roca C, Balanzó X, Fernández-Roure JL, Sauca G, Savall R, Gascón J et al. Enfermedades importadas en inmigrantes africanos: estudio de 1321 pacientes. Med Clín (Barc). 2002; 119(16):616619.

25. Gispert R, Clot-Razquin G, Torné MM, BosserGiralt R, Freitas-Ramirez A. Diferencias en el perfil reproductivo de mujeres autóctonas e inmigrantes residentes en Cataluña. Gac Sanit. 2008; 22(6):574-7.

26. Rodríguez E, Lanborena N, Pereda C, Rodríguez A. Impacto en la utilización de los servicios sanitarios de las variables sociodemográficas, estilos de vida y autovaloración de la salud por parte de los colectivos de inmigrantes del país vasco, 2005. Rev Esp Salud Pública. 2008; 82:209-220.

27. Puig Sola C, Zarzoso Palomero A, García-Algar O, Cots REguant F, Burón Pust A, Castells Oliveres X, Vall Combelles O. Ingreso hospitalario de los reción nacidos según origen étnico y el país de procedencia de los progenitores en un área urbana de Barcelona. Gac Sanit. 2008; 22(6):555-64

28. Jones EM, Cason CL, BOnd ML. Access to preventive health care: is method of payment a barrier for immigrant hispanic women?. Womens Health Issues. 2002; 12:129-137.

29. Reijneveld SA. Reported health, lifestyles, and use of health care of first generation immigrants in The Netherlands: do socioeconomic factors explain their adverse position? J Epidemiol Community Health. 1998; 52:298-304

30. Pantzer K, Rajmil L, Tebé C, Codina F, Serra-sutton V, Ferrer M, et al. Health related quality of life in immigrants and native school aged adolescents in Spain. J Epidemiol Community Health. 2006; 60(8): 694-698.

31. Stronks K, Ravelli AC, Reijneveld SA. Immigrants in the Netherlands: equal access for equal needs? J Epidemiol Community Health. 2001; 55:701-707.

32. Ricart M. Los inmigrantes llegan sanos y enferman por su cambio de vida. La Vanguardia. Viernes 12 de diciembre de 2003.p. 31.

33. Malmusi D, Lopez JMJi. Recomendaciones para la investigación e información en salud sobre definiciones y variables para el estudio de la población inmigrante de origen extranjero. Revista Española de Salud Pública. 2007; 81(004):399409.

34. Informe sobre el desarrollo humano [sede web]. New York: Programa de las Naciones Unidas para el Desarrollo; 2001 [acceso 24 de mayo de 2008]. Fukuda-Parr S, Jahan S, Noman O, Raworth K, Hill R, Mezzetti P, et al. Poner el adelanto tecnológico al servicio del desarrollo humano. Disponible en http://hdr.undp.org

35. Gené J, Marzo M. La direcció clínica en l'organització primària. Fulls econòmics del sistema sanitari, 2003; 37: [29-32]. Disponible en http://sumaris.cbuc.es

36. Van Weel C, König-Zhan C, Touw-Otten FWMM, van Duijn NP, Meyboom B. Measuring functional health status with the COOP/WONCA Charts. A manual. Netherlands: World Organization of Family Doctors (WONCA); 1995. Disponible en http://www.globalfamilydoctor.com

37. Saurina C, Saez M, Coromina L1, Pons JC, Vallllosera L, inventores. Enquesta d'estat de salut i utilització dels serveis sanitaris a la Regió Sanitaria Girona (RSG). Patente Española 5908. BOPI 15-06-2007.

38. Borrell C, García-Calvente MM, Martí-Boscà JV. La salud pública desde la perspectiva de género y clase social. Gac Sanit. 2004; 18(Supl 1):2-6. 
39. Sanz B, Blasco T. Características sociodemográficas de la población inmigrante diagnosticada de tuberculosis en la Comunidad de Madrid. Gac Sanit. 2007; 21:142-146.

40. Jylha M., Guralnik JM, Ferrucci L, Jokela J, Heikkinen E. Is self-rated health comparable across cultures and genders? J Gerontol. 1998; 53: 144-52.

41. Cooper H. Investigating socio-economic explanations for gender and ethnic inequalities in health. Soc Sci Med. 2002; 54: 693-706.

42. lbares MP, Ramos JM, Belinchón I, Betlloch I, Pastor N, Botella R. Análisis de la demanda asistencial en dermatología de la población inmigrante. Gac Sanit. 2008; 22(2):133-6.

43. Uiters E, Deville WLJM, Foets M, Groenewegen PP. Use of health care services by ethnic minorities in The Netherlands: do patterns differ? Eur J Public Health. 2006; 4: 388 - 393.

44. Hjern A, Haglund B, Persson G, Rosén M., Is there equity in access to health services for ethnic minorities in Sweden? Eur J Public Health. 2001; 11(2): 147-52;

45. Baker DW, Stevens CD, Brook RH. Determinants of emergency department use: are race and ethnicity important? Ann Emer Med. 1996, 28: 677-82.

46. Jansa JM. Inmigración y envejecimiento, nuevos retos en salud publica.Gac Sanit. 2006 Mar; 20 Suppl 1:10-4
47. Cots F, Castells X, Olle C, Manzanera R, Varela J, Vall O. Perfil de la casuística hospitalaria de la población inmigrante en Barcelona. Gac Sanit. $2002 ; 16$ (5):376-84

48. Sundquist J. Migration, equality and access to health care services. J Epidemiol Community Health, 2001; 55: 691- 692.

49. McDonald J T, Kennedy S. Insights into the "Healthy immigrant effect": health status and health use of immigrants to Canada. Soc Sci Med. 2004; 59: 1613-1627.

50. Rodriguez E, Lanborena N, Pereda C, Rodríguez A. Impacto en la utilización de los servicios sanitarios de las variables sociodemográficas, estilos de vida y autovaloración de la salud por parte de los colectivos de inmigrantes del País Vasco. Rev Esp Salud Pública. 2008; 82:209-220.

51. Saurina C, Vall-llosera L, Saez M, González S, Renart G, Rué M, Cots F, Muñoz MD. Immigració i salut: estat de salut, necessitats i utilització dels serveis d'atenció primària. Barcelona: Generalitat de Catalunya. Departament d'Acció Social i Ciutadania. Col·lecció Ciutadania i Immigració 2008; 1:153-174.

52. Sen G, George A, Östlin P. Engendering Health Equity: A review of research and policy in Sen $\mathrm{G}$, George A, Östlin P. (Eds.). Engendering International Health - The Challenge of Equity Cambridge: MIT Press. 
